\title{
A lesson from inappropriate single closure of a perforation during endoscopic submucosal dissection
}

We report repeated perforations during colorectal endoscopic submucosal dissection (ESD) and successful endoscopic closure.

A 72-year-old man with a laterally spreading tumor, $25 \mathrm{~mm}$ in diameter, in the lower rectum was referred for ESD. ESD was started from the anal side using a DualKnifeJ (Olympus, Tokyo, Japan). The lesion had severe fibrosis in the submucosal layer. The submucosal layer was not clearly identified, and a perforation occurred. Clipping was immediately performed [1]; however, the clip interfered with subsequent submucosal dissection ( $>$ Fig. 1 a, - Video 1), and another perforation occurred. Clipping was immediately performed. ESD was continued from the oral side with retroflexed endoscopic view. Carbon dioxide insufflation is essential in this situation [2], and adequate colon preparation is also an important factor when considering the management of such complications [3]. The clips interfered with final submucosal dissection. We could not pull the clip out with a grasping forceps (\$Fig.1 b), and there was also concern about causing a larger perforation if we forcibly pulled it. Therefore, we had no choice but to cut the muscle layer with the DualKnifeJ to achieve en

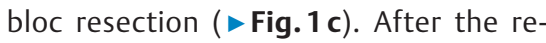
moval of the specimen, the perforations were closed using endoclips. Furthermore, complete closure was performed using the endoloop/clips technique in a purse-string fashion [4, 5] ( $\mathbf{F i g} .1 \mathrm{~d}$ ).

A lesson from this case is that immediate clipping after perforation could interfere with subsequent submucosal dissection. Before the application of the first clip, additional submucosal dissection should be performed in order to make sufficient space for clipping.

Endoscopy_UCTN_Code_TTT_1AQ_2AD
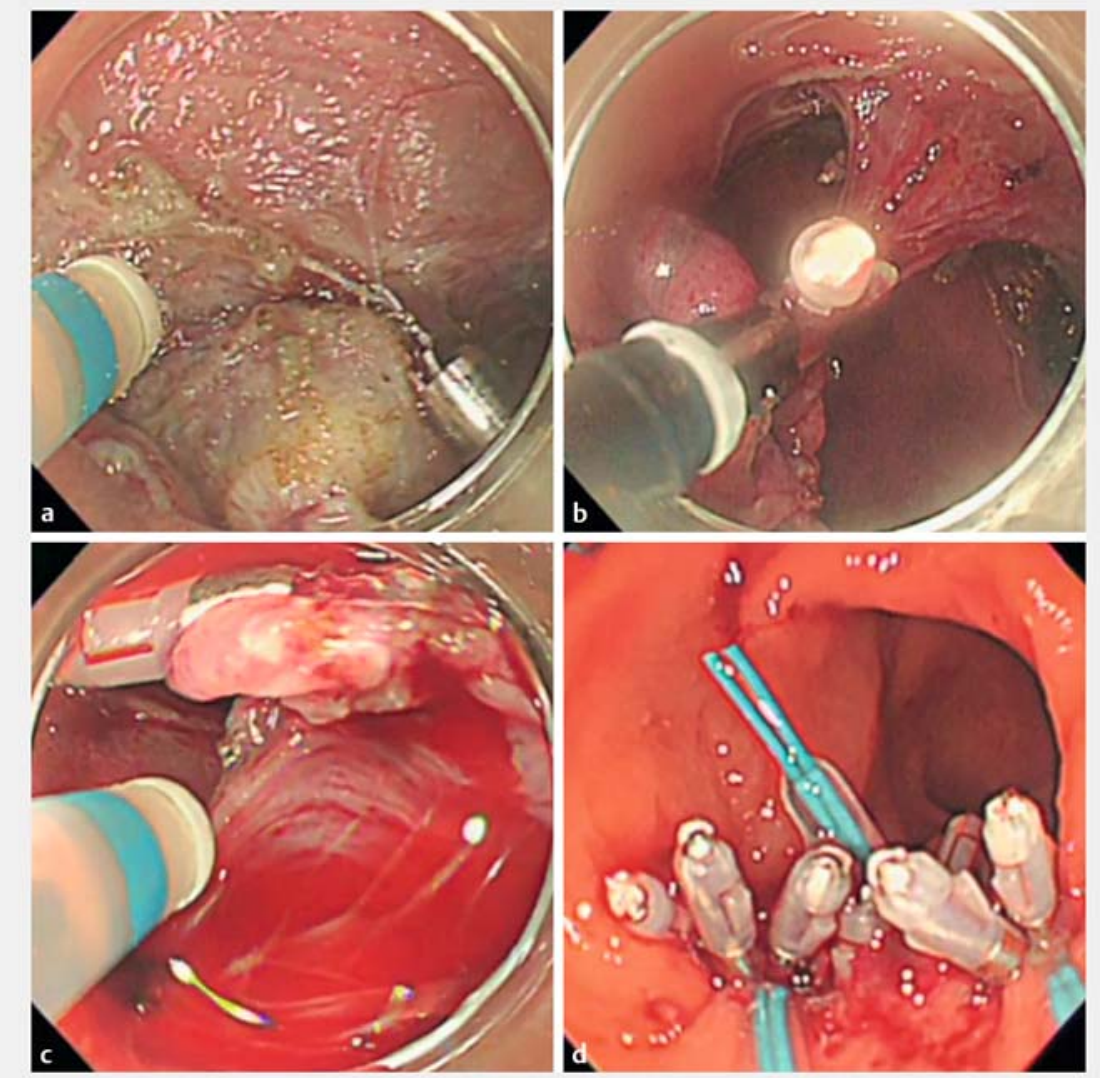

- Fig. 1 Repeated perforations during colorectal endoscopic submucosal dissection. a The clip for a perforation interfered with subsequent submucosal dissection. $\mathbf{b}$ The clip could not be pulled out with a grasping forceps. $\mathbf{c}$ We had no choice but to cut the muscle layer with the DualKnifeJ (Olympus, Tokyo, Japan) to achieve en bloc resection. $\mathbf{d}$ Complete closure was performed using the endoloop/clips technique in a purse-string fashion.

\section{Competing interests}

None

The authors

Yukie Sunata ${ }^{1}$, Toshihiro Nishizawa' ${ }^{1,2,3}$, Satoshi Kinoshita ${ }^{1,2,3}$, Kaoru Takabayashi ${ }^{1,4}$, Toshio Uraoka ${ }^{1,3}$

1 Department of Gastroenterology, National Hospital Organization Tokyo Medical Center, Tokyo, Japan
2 Department of Gastroenterology and Hepatology, Keio University School of Medicine, Tokyo, Japan

3 Division of Research and Development for Minimally Invasive Treatment, Cancer Center, Keio University School of Medicine, Tokyo, Japan

4 Center for Diagnostic and Therapeutic Endoscopy, Keio University School of Medicine, Tokyo, Japan 


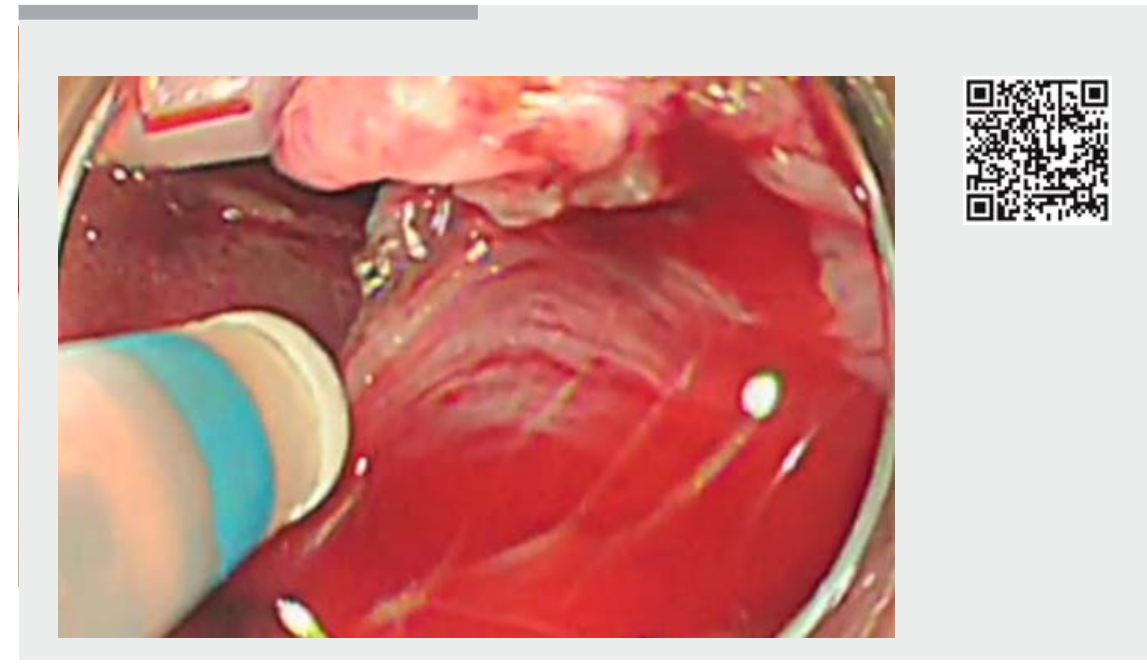

Video 1 Inappropriate single closure of a perforation during endoscopic submucosal dissection (ESD). Rectal ESD was performed. The lesion had severe fibrosis in the submucosal layer. A small perforation occurred, and clipping was immediately performed. However, the clip interfered with subsequent submucosal dissection, and another perforation occurred. The previous clips interfered with final submucosal dissection, and we had no choice but to cut the muscle layer. Before the application of the first clip, we should consider whether more dissection is needed before effective clipping. Additional submucosal dissection should be performed in order to make sufficient space for clipping.

\section{Corresponding author}

\section{Toshio Uraoka, MD, PhD}

Department of Gastroenterology, National Hospital Organization Tokyo Medical Center, 2-5-1 Higashigaoka, Meguro-ku, Tokyo 1528902, Japan

Fax: +81-3-53633967

toshi_urao@yahoo.co.jp

turaoka@a3.keio.jp

\section{References}

[1] Tanaka S, Kashida H, Saito Y et al. JGES guidelines for colorectal endoscopic submucosal dissection/endoscopic mucosal resection. Dig Endosc 2015; 27: 417-434

[2] Saito Y, Uraoka T, Matsuda T et al. A pilot study to assess the safety and efficacy of carbon dioxide insufflation during colorectal endoscopic submucosal dissection with the patient under conscious sedation. Gastrointest Endosc 2007; 65: 537-542

[3] Paspatis GA, Dumonceau JM, Barthet M et al. Diagnosis and management of iatrogenic endoscopic perforations: European Society of Gastrointestinal Endoscopy (ESGE) Position Statement. Endoscopy 2014; 46: $693-$ 711

[4] Matsuda T, Fujii T, Emura F et al. Complete closure of a large defect after EMR of a lateral spreading colorectal tumor when using a two-channel colonoscope. Gastrointest Endosc 2004; 60: 836-838

[5] Katsinelos P, Chatzimavroudis G, Terzoudis S et al. The endoloop-clips technique for closure of large iatrogenic colonic perforations. Endoscopy 2010; 42: 343

\section{Bibliography}

DOI https://doi.org/10.1055/s-0043-121138

Published online: 3.11.2017

Endoscopy 2018; 50: E25-E26

(c) Georg Thieme Verlag KG

Stuttgart · New York

ISSN 0013-726X

\section{ENDOSCOPY E-VIDEOS}

https:/|eref.thieme.de/e-videos

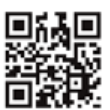

Endoscopy E-Videos is a free access online section, reporting on interesting cases and new

techniques in gastroenterological endoscopy. All papers include a high quality video and all contributions are freely accessible online.

This section has its own submission website at https://mc.manuscriptcentral.com/e-videos 